\title{
Estrus characteristics, ovarian response to synchro- nization hormones, and fertility of crossbred dairy heifers managed under a semi-intensive system
}

\author{
Tilaye Demissie ${ }^{1^{*}}$, Tefera Yilma ${ }^{1}$, Tamrat Degefa ${ }^{2}$, Adise Ambilo ${ }^{3}$, Tsigereda Tadesse, ${ }^{3}$ \\ and Alemayehu Lema ${ }^{1}$ \\ ${ }^{1}$ Addis Ababa University, College of Veterinary Medicine \& Agriculture \\ ${ }^{2}$ Ethiopian Agricultural Research Institute \\ ${ }^{3}$ Wolaita Sodo University, College of Veterinary Medicine. \\ *Corresponding Author: tilayedemissie2000@gmail.com or tilaye.demissie@aau.edu.et
}

\begin{abstract}
This study aimed to characterize estrus sign/s which best predict the time of ovulation and determine ovarian responses to different synchronization protocols and conception rates to fixed-time artificial insemination in Boran*Holstein crossbred heifers. In the first part of the study, twenty-seven heifers were observed for estrus signs (from induced and natural) and the relationship of various estrus signs with ovulation time was evaluated by using ultrasonography. In the second part, 91 Boran*Holstein crossbred heifers were randomly grouped into three groups. Group one heifers $(n=28)$ received $100 \mu \mathrm{g}$ gonadotropin-releasing hormone $(\mathrm{GnRH})$ on day zero (D0), $500 \mu \mathrm{g}$ prostaglandin F2a (PGF2a) on day 7 and 100ug of GnRH on day 9. Group 2 heifers $(n=32)$ were treated as group one but additionally received progesterone as controlled internal drug release (CIDR). Group three heifers $(n=31)$ were treated as those in group 2 but without injection with $\mathrm{GnRH}$ on day 0 . In all the 3 groups' insemination was made at $19 \mathrm{~h}$ of the second $\mathrm{GnRH}$. The results showed that irrespective of estrus source type (induced or natural), score for standing to be mounted, mounting other heifers, and non-receptive mount by other heifers showed a strong positive correlation with ovulation time $(\mathrm{r}=0.67$, $P<0.05)$. Standing estrus duration, and time elapsed from standing estrus to ovulation were shorter $(P<0.05)$ in induced estrus. The conception rate was $39.3 \%$ in synchronized ovulation in the absence of CIDR. The conception rate in timed insemination was $56.3 \%$ when ovulation was synchronized by combining CIDR, PGF2a, and GnRH. In conclusion injection of GnRH on day zero together with treatment with CIDR improved ovulation rate, the number of
\end{abstract}


new corpus luteum, and conception rate. Heifers that ovulated within the first $24 \mathrm{~h}$ after timed insemination had a higher $(P<0.05)$ conception rate than heifers ovulated after $24 \mathrm{~h}$ of timed insemination. Cycling heifers at day zero had a greater $(P<0.05)$ conception rate than non-cycling.

Keywords: Conception rate; crossbred dairy heifers; estrus sign; ovarian response; synchronization.

\section{Introduction}

Estrus induction by PGF2 $\alpha$ and subsequent insemination is used to speed up cattle genetic improvement in Ethiopia. The average conception rates after estrus induction and insemination were reported to be lower than $40 \%$ (Gizaw et al., 2016). Many factors influence the efficacy of prostaglandin-based estrus induction; among which are the stage of the estrus cycle at prostaglandin administration, estrus sign detection, and submission of animals in estrus for artificial insemination (AI). Previous studies (Bainesagne, 2015; Destalem, 2015 ) indicate that $24.2 \%$ to $50.9 \%$ of cows had milk progesterone concentration higher than $3 \mathrm{ng} / \mathrm{ml}$ at insemination, which strongly indicated that insemination was done at the wrong time.

Protocols that allow for AI without the need for estrus detection are a better alternative to increase the number of animals inseminated at an appropriate time. These protocols need manipulation of follicular waves and ovulation before insemination. These protocols have been successfully applied in Bos taurus herds. However, where the environment is predominantly subtropical to tropical, and when Bos taurus breed was crossed to Bos indicus, a decrease in conception rates to ovulation synchronization and timed AI has been reported (Hiers et al., 2003). When dairy heifers of Bos taurus breed are subjected to Ovsynch protocol, a greater incidence of estrus before timed artificial insemination (TAI) was frequently observed (Rivera et al., 2004) and that leads to a low conception rate to TAI for dairy heifers. Suppression of premature estrus expression using Controlled Internal Drug Release (CIDR) improves conception rate to TAI in taurine dairy heifers.

Most of the data on ovulation synchronization and conception rate to timed AI was from sub-tropical countries like Brazil, Argentina, and the Southern United States. Similarly, the zebu cattle used for crossing to Bos taurus in these 
countries were commonly the Nelore breed. Little is known on the subject in tropical African and non-Nelore zebu cattle crossed to Bos taurus cattle. The objectives of the present study were, therefore, to characterize estrus sign/s which best predict the time of ovulation, and determine ovarian responses to different synchronization protocols and conception rates to fix time of artificial insemination in crosses of Bos indicus X Bos taurus.

\section{Materials and methods}

\section{Study area}

This study was conducted in six dairy farms, three farms from Bishoftu, and three from Modjo towns. Both towns are located in the Eastern Shewa Zone of Oromia Regional State. Bishoftu is located at $47 \mathrm{~km}$ southeast of Addis Ababa at $8^{\circ} 45^{\prime} \mathrm{N}$ latitude, $38^{\circ} 59^{\prime} \mathrm{E}$ longitude, and an elevation of 1885 meters above sea level. The mean annual rainfall of the town is $866 \mathrm{~mm}$ with a bimodal pattern. The mean annual minimum and maximum temperatures are $14^{\circ} \mathrm{C}$ and $26^{\circ} \mathrm{C}$, respectively and relative humidity was $61.3 \%$. Modjo town is located at $66 \mathrm{Km}$ southeast of Addis Ababa at $8^{\circ} 35^{\prime} \mathrm{N}$ latitude and $39^{\circ} 7^{\prime} \mathrm{E}$ longitude. The altitude is 1790 meters above sea level. The average annual rainfall, temperature, and mean relative humidity are $776 \mathrm{~mm}, 19.4^{\circ} \mathrm{C}$, and $59.9 \%$, respectively (National Meteorology, 2010, unpublished data).

\section{Experimental design and treatments protocols}

This study has two experiments. Experiment one (Exp 1) involves 27 crossbred dairy heifers aged between 18 and 26 months and with a mean body condition score of $3.7 \pm 0.2$ (on 1-5 scale, Ferguson et al., 1994). The heifers were given

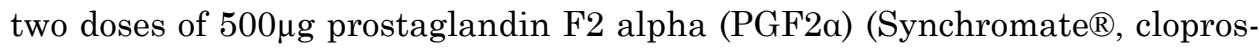
tenol sodium, Warburg, Germany) at 11 days intervals. After gathering data on estrus, the heifers were rested for one estrus cycle and crossed over for gathering data on natural estrus. In natural estrus, an observation started from day 16 of the previous estrus. Experiment 2 (Exp2) involved 91 crossbred dairy heifers randomly assigned to three groups. In group 1, 28 heifers received $100 \mu \mathrm{g}$ gonadotrophin-releasing hormone $(\mathrm{GnRH})$ through IM injection (Gonadorelin diacetate tetrahydrate, Merial limited Duluth, USA) on day 0

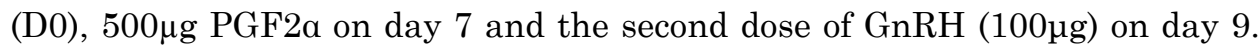
The group was assigned as GnRH-PGF2a-GnRH (GPG). Group 2 (CIDR-GPG) heifers $(n=32)$ received all treatments of Group 1 and were additionally treated with CIDR (CIDR 1380, EAZI BREED ${ }^{\text {TM }}$, New Zealand) from day 0 to 7 and at 
CIDR removal (D7) PGF2a was given. Group 3 (CIDR-P-G) heifers $(n=31)$ had the same treatment as those in Group 2 but without the initial (day 0) $\mathrm{GnRH}$ treatment. In all groups, heifers were inseminated using frozen-thawed semen at $19 \mathrm{~h}$ of the last $\mathrm{GnRH}$ injection.

\section{Estrus detection}

After $24 \mathrm{~h}$ of the second PGF2a injection in experiment 1 , heifers were visually observed every $3 \mathrm{~h}$ for 30 minutes ( $6 \mathrm{am}, 9 \mathrm{am}, 12 \mathrm{am}, 3 \mathrm{pm}, 6 \mathrm{pm}, 9 \mathrm{pm}$, $12 \mathrm{pm}$, and $3 \mathrm{am}$ ) for estrus sign for $120 \mathrm{~h}$ in estrus induced group or starting from day 16 of the former estrus in spontaneous estrus. Observed estrus signs were scored using a method recommended by van Eerdenburg et al. (1996) with slight modifications in relation to signs associated with vaginal anatomy, which were not considered in the present study. Each time a symptom was observed, the assigned number of points was recorded (Table 1). If the sum of the points exceeded 50 during two consecutive observation periods, a heifer was considered to be in estrus. A heifer was said to be in standing estrus when it stood receptive on mounting by another heifer, with or without the other symptoms of estrus. Cessation of estrus was when heifers are no more receptive to mounting after previously being in standing estrus.

Table 1. Estrus scoring criteria. A heifer was considered to be in heat when the cumulative score was 50 at two observations (Modified from van Eerdenburg et al., 1996).

\begin{tabular}{lc}
\hline Estrus sign & Points assigned \\
\hline Flemen & 3 \\
Restlessness & 5 \\
Bellowing (repeated) & 5 \\
Sniffing vagina of another cow & 10 \\
Being mounted but not standing & 10 \\
Resting with chin on another cow & 15 \\
Mounting (or attempting) other cows & 35 \\
The mounting head side of another cow & 35 \\
Standing heat & 100 \\
\hline
\end{tabular}




\section{Ovarian ultrasonography}

Mindray ultrasound (DP.50vet, China) with a $7.5 \mathrm{MHz}$ linear array rectal probe was used. In Experiment 1, starting from 24h of the second PGF2a in estrus induced group or day 16 of previously induced estrus in natural estrus group, ovarian structures were scanned twice a day $(8: 00 \mathrm{am} ; 8: 00 \mathrm{pm})$ until heifers were in standing estrus. Beginning from first standing estrus, ovarian examinations were made at every $6 \mathrm{~h}$ interval until heifers were off estrus. From off estrus to ovulation, ovarian examinations were made every $3 \mathrm{~h}$. In Experiment 2, ovaries were monitored on days $0,2,7,8$, and 9, and then at $24 \mathrm{~h}, 36 \mathrm{~h}$, and $48 \mathrm{~h}$ after day 9 to assess ovulatory outcomes and size of the ovulatory follicle. On ultrasonographic examination, the size of follicles, the location of the dominant follicle, and the corpus luteum were recorded. Ultrasonographic examinations were also performed on day 10 after AI to determine CL diameter. Ovulation was confirmed on the disappearance of a previously identified dominant follicle $(\geq 8 \mathrm{~mm})$ and the presence of CL on the same site (modified from Ginther et al., 1989).

\section{Pregnancy determination}

Conception was checked on day 32 of AI. On ultrasound, the presence of a fluidfilled uterine horn and a conceptus were used as positive indicators of conception (Fricke et al., 1998).

\section{Statistical analysis}

Duration of estrus was calculated by subtracting the time initial estrus was detected from the time the last standing mount was detected. The interval from PGF2 $\alpha$ injection to the onset of estrus was calculated as the interval from PGF2 $\alpha$ to the first estrus detected. The estrous response was defined as the number of heifers displaying estrus after PGF2a injection divided by the total number of heifers treated. To evaluate the length of time intervals of each behavioral estrous sign to an ovulation time, analysis of variance (ANOVA) in STATA software was used. All heifers that ovulated between $10 \mathrm{pm}$ and 6 am were not included in the ovulation time interval as determining ovulation every $3 \mathrm{~h}$ within this time gap was interrupted in some heifers. Pearson correlation was used to evaluate the correlation between estrus signs and ovulation time, follicle size at standing estrus and ovulation, follicle size and ovulation time, ovulation from the same ovary at different estrus. $P<0.05$ was considered to be significant. Conception rate was defined as the number of heifers 
that became pregnant, divided by the number of heifers that were inseminated. All count measurements were indicated as mean \pm SE (standard error of the mean). Five heifers that did not respond to PGF2a were excluded from estrus induced group.

\section{Results}

\section{Estrus behavior characteristics and frequencies}

The detailed descriptions of estrus signs manifested are listed in Table 2. There was no statistically significant difference among induced and natural estrus $(P>0.05)$ on the frequency of various estrus signs. However, there was a tendency that standing to be mounted, attempt to mount other heifers, and non-receptive mount were frequently seen in heifers from the induced group. Irrespective of estrus type (induced or natural), sniffing ano-vaginal region and resting chin on other heifers were the most frequently observed estrus signs. Estrus signs were more frequently observed when more than two heifers were in estrus at the same time.

Table 2. The frequency and percentages of estrus sign observed (mean $\pm \mathrm{SE}$ ) in relation to estrus type and number of heifers in estrus

\begin{tabular}{|c|c|c|c|}
\hline \multirow[t]{3}{*}{ Estrus sign } & \multicolumn{3}{|c|}{ Mean frequency $( \pm \mathrm{SE})$ and (percent) of estrus signs } \\
\hline & Induced estrus & Natural estrus & \\
\hline & $\begin{array}{l}\geq \text { two heifers were in estrus } \\
\text { (synchronized) }\end{array}$ & $\begin{array}{l}\text { One heifer in } \\
\text { estrus }\end{array}$ & $\begin{array}{l}\geq \text { two heifers } \\
\text { in estrus }\end{array}$ \\
\hline Sniffing & $20.2 \pm 8.3,(92)^{\mathrm{a}}$ & $15.6 \pm 3.6,(90)$ & $16.3 \pm 2.7,(94)$ \\
\hline Chin resting & $22.6 \pm 10.5,(90)$ & $18.5 \pm 5.2,(96)$ & $21.2 \pm 10.6,(94)$ \\
\hline Mounting others & $9.9 \pm 4.2,(82)$ & $6.7 \pm 2.6,(71)$ & $7.9 \pm 3.2,(74)$ \\
\hline Mount not received & $8.2 \pm 1.5,(64)^{\mathrm{a}}$ & $2.6 \pm 1.2,(63)$ & $4.2 \pm 1.8,(69)$ \\
\hline $\begin{array}{l}\text { Standing estrus } \\
\text { (mounts received) }\end{array}$ & $7.5 \pm 2.8,(63.6)$ & $4.7 \pm 1.5,(54)^{\mathrm{a}}$ & $7.2 \pm 2.3,(59.1)$ \\
\hline Bellowing & $9.4 \pm 3.7,(58.9)$ & $7.9 \pm 2.5,(50.9)$ & $8.8 \pm 3.3,(54.9)$ \\
\hline
\end{tabular}

\section{Estrus duration and time of ovulation}

The details of durations of different estrus behaviors and intervals from different estrus signs to ovulation are listed in Table 3. The mean ( $\pm \mathrm{SE})$ estrus length was not affected by estrus type (induced and natural). The interval from

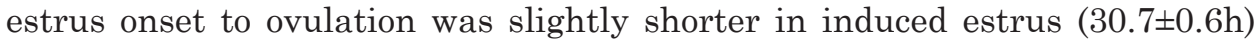


than natural estrus $(32.1 \pm 0.8 \mathrm{~h})$ although the difference was not statistically significant $(P>0.05)$. Heifers that showed less than $24 \mathrm{~h}$ estrus length in the induced group were also likely to have less than $24 \mathrm{~h}$ estrus length when crossed over to the natural estrus manifestation group $(r=0.85 ; P<0.05)$. Standing estrus was started at an average of $7.1 \pm 0.4 \mathrm{~h}$ of onset of estrus in induced estrus and $8.6 \pm 2.0 \mathrm{~h}$ in natural estrus (Table 3). In all heifers that ovulated, ovulation occurred within the first $24 \mathrm{~h}$ after the end of estrus. From the total of 32 ovulations observed, the large majority (60.4\%) ovulated from the right ovaries $(P<0.05)$. Heifers that had ovulations from right ovaries in estrus induced group were more likely to successively ovulate from the right ovaries $(\mathrm{r}=$ $0.6, P<0.05)$ when crossed over to ovulate from natural estrus. In the present study, it was found that standing to be mounted and mounting other heifers have a $100 \%$ correlation with ovulation rate $(\mathrm{r}=1)$ and interestingly the time of ovulation was quite consistent (range $16-21 \mathrm{~h}$ ) and was with minimum variation between individual heifers with standing to be mounted.

Table 3. Duration of estrus, estrus onset to standing heat, and estrus signs to ovulation (hrs)

\begin{tabular}{|c|c|c|c|c|}
\hline \multirow[t]{3}{*}{ Estrus sign } & \multicolumn{4}{|c|}{ Estrus type \& interval to ovulation } \\
\hline & \multicolumn{2}{|c|}{ Induced } & \multicolumn{2}{|c|}{ Natural } \\
\hline & $\operatorname{Mean} \pm \mathrm{SE}$ & Range & Mean \pm SE & Range \\
\hline Duration of estrus & $18.4 \pm 4.2$ & $11.0-29.0$ & $20.2 \pm 3.9$ & $10.0-30.0$ \\
\hline $\begin{array}{l}\text { Interval from onset to standing } \\
\text { estrus }\end{array}$ & $8.1 \pm 0.6$ & $6.0-20.0$ & $10.4 \pm 1.5$ & $8.0-23.0$ \\
\hline Standing estrus duration & $7.1 \pm 0.4^{\mathrm{a}}$ & $5.0-12.0$ & $10.6 \pm 2.0^{\mathbf{b}}$ & $3.0-16.0$ \\
\hline Estrus onset to ovulation & $30.7 \pm 0.6$ & $18.0-38.0$ & $32.1 \pm 0.8$ & $17.0-39.4$ \\
\hline Estrus end to ovulation & $12.3 \pm 1.1$ & $6.0-20.0$ & $15.4 \pm 1.2$ & $6.4-20.3$ \\
\hline Standing estrus to ovulation & $19.0 \pm 1.9^{\mathrm{a}}$ & $12.0-21.0$ & $25.0 \pm 4.0^{\mathbf{b}}$ & $15.0-26.0$ \\
\hline Mounting other heifers to ovulation & $26.8 \pm 4.3^{\mathrm{a}}$ & $16.0-35.4$ & $30.3 \pm 2.1^{b}$ & $21.2-43.5$ \\
\hline Non-receptive mount to ovulation & $24.7 \pm 5.4$ & $10.5-45.0$ & $21.5 \pm 1.9$ & $16.4-39.6$ \\
\hline Sniffing (start) to ovulation & $29.4 \pm 1.2$ & $20.0-38.5$ & $31.4 \pm 5.3$ & $22.0-36.5$ \\
\hline Chin resting (start) to ovulation & $30.5 \pm 5.2$ & $17.0-40.5$ & $30.5 \pm 4.7$ & $20.0-37.0$ \\
\hline
\end{tabular}

\section{Follicle and corpus luteum size by types of estruses}

The mean $( \pm \mathrm{SE})$ diameter of the larger follicle at first standing estrus did not differ significantly ( $P>0.05)$ due to estrus type (8.64 \pm 1.32 in induced; $9.22 \pm 0.73$ in natural estrus). Similarly, the mean $( \pm \mathrm{SE})$ diameter of the ovulatory follicle 
didn't show a significant difference $(P>0.05)$ between induced $(16.15 \pm 0.53 \mathrm{~mm})$ and natural (17.43 \pm 1.53$)$ ovulations. There was a strong positive correlation between follicle size at standing estrus and size at ovulation in which heifers with large follicles at standing estrus had larger ovulatory follicles at ovulation $(\mathrm{r}=0.72, P<0.05)$. There was also a positive correlation between follicle size and ovulation time in which, heifers with larger follicles at standing estrus ovulated earlier than heifers with smaller follicles $(\mathrm{r}=0.15, P>0.05)$. The diameter of CL did not significantly differ $(P>0.05)$ between induced (17.5 \pm 1.6 $\mathrm{mm})$ and natural estrus groups $(17.7 \pm 2.2 \mathrm{~mm})$.

\section{Ovulation rate and ovulation time}

The details of the ovulation rate to GnRH and time of ovulation were described in Table 4. Ovulation to day $0 \mathrm{GnRH}$ injection was significantly higher $(P<0.05)$ in heifers of the GPG group (28.6\%) than the CIDR-GPG group (12.5\%). Ovulation to day $9 \mathrm{GnRH}$ injection was significantly higher $(P<0.05)$ in the CIDRGPG group than CIDR-P-G and GPG group. In the CIDR-GPG group, all heifers ovulated to day $0 \mathrm{GnRH}$ injection ovulated also to day $9 \mathrm{GnRH}$ injection. However, in the GPG group, $21.1 \%$ of heifers that ovulated to day $0 \mathrm{GnRH}$ injection did not ovulate to day $9 \mathrm{GnRH}$ injection.

The mean time (h) from PGF2 treatment to ovulation and from GnRH injection on day 9 to ovulation was not affected by treatment type $(P>0.05)$ except in the CIDR-GPG group which had a significantly longer mean time (h) from PGF2a treatment to ovulation $(P<0.05)$ than the other groups. When the distribution of time to ovulation after $\mathrm{GnRH}$ injection on day 9 was considered, more heifers (52.6\%) from the GPG group ovulated within the first $24 \mathrm{~h}$ than the remaining groups (Table 4). In about $73.7 \%$ of heifers from the GPG group, $78.6 \%$ from the CIDR-GPG group, and $83.3 \%$ from the CIDR-P-G group that ovulated to day $9 \mathrm{GnRH}$ injection, the ovulations were from a follicle other than the large follicle that was present at the start date.

\section{Diameter of follicles by treatment group}

The mean size of the large follicle on day 0 did not differ $(P>0.05)$ among the treatment groups (Table 4). Similarly, the mean size of the larger follicle at day 7 (48h of day $0 \mathrm{GnRH}$ injection), the mean size of the large follicle of on day $9 \mathrm{GnRH}$ injection, and the mean size of pre-ovulatory follicles that eventually ovulated did not statistically differ $(P>0.05)$ among the treatment groups 
(Table 4). However, when the data was combined with heifers ovulating from natural estrus (from experiment one), the mean diameter of the pre-ovulatory follicle that eventually ovulated was significantly greater $(P<0.05)$ in natural ovulation (18.43 \pm 1.53$)$ than hormone-treated groups.

\section{Corpus luteum status by treatments}

A large majority of heifers $(60.4 \%)$ had visible CL on day 0 indicating that they were cyclic. The presence of a new CL on day 7 was greater $(P \leq 0.05)$ for the CIDR-GPG group than the CIDR-P-G group. Ovulation to treatment with $\mathrm{GnRH}$ on day 0 resulted in a greater proportion of heifers with visible CL in the CIDR-GPG group than the CIDR-P-G group on day 7 (Table 4). The number of total CLs after PGF2a injection on day 7 was significantly greater $(P<0.05)$ in heifers receiving GnRH on day 0 (CIDR-GPG) than those without GnRH treatment on day 0. Similarly, the proportion of heifers that have new $\mathrm{CL}$ on day 7 was significantly higher $(P<0.05)$ in heifers that received $\mathrm{GnRH}$ on day 0 .

Table 4. Ovarian characteristic and response to treatments

\begin{tabular}{|c|c|c|c|}
\hline \multirow[t]{2}{*}{ Ovarian status } & \multicolumn{3}{|c|}{ Treatment group } \\
\hline & GPG & CIDR-GPG & CIDR-P-G \\
\hline PGF2a-ovulation interval (h) $\dagger$ & $80.9 \pm 2.7$ & $99.5 \pm 2.8$ & $82.7 \pm 1.3$ \\
\hline Ovulation due to $\mathrm{D} 0 \mathrm{GnRH} \dagger \dagger$ & $28.6 \%^{\mathrm{a}}$ & $12.5 \%^{\mathbf{b}}$ & $0 \%{ }^{\mathrm{c}}$ \\
\hline Ovulation due to D9 GnRH & $67.9 \%^{\mathrm{a}}$ & $87.5 \%^{\mathbf{b}}$ & $77.4 \%$ c \\
\hline D9 GnRH to ovulation interval(h) $\dagger$ & $24.3 \pm 1.6$ & $28.5 \pm 1.01$ & $27.4 \pm 1.3$ \\
\hline $\begin{array}{l}\text { Ovulation in } \leq 24 \text { h of } \mathrm{GnRH} \text { treatment } \\
(\%)\end{array}$ & $52.6 \%$ & $42.9 \%$ & $45.8 \%$ \\
\hline Ovulation in >24 of GnRH treatment (\%) & $47.4 \%$ & $57.1 \%$ & $54.2 \%$ \\
\hline Follicle diameter at PGF2a & $8.4 \pm 0.2$ & $9.2 \pm 0.3$ & $9.4 \pm 0.3$ \\
\hline Follicle diameter $24 \mathrm{~h}$ after PGF2a & $10.0 \pm 1.2$ & $10.2 \pm 0.6$ & $11 \pm 1.4$ \\
\hline Follicle diameter at D9 GnRH & $11.8 \pm 1.7$ & $12.7 \pm 2.5$ & $12.5 \pm 0.7$ \\
\hline $\begin{array}{l}\text { Follicle diameter immediate to } \\
\text { ovulation } \dagger\end{array}$ & $14.3 \pm 2.2$ & $15.2 \pm 1.9$ & $13.5 \pm 1.7$ \\
\hline CL presence on d0 (\%) & $60.7 \%$ & $65.6 \%$ & $61.3 \%$ \\
\hline New CL on D7(\%) ††† & $35.7 \%{ }^{\mathrm{a}}$ & $47.5 \%{ }^{\mathbf{b}}$ & $16.1 \%$ c \\
\hline Total CL on D7 (\%) & $82.1 \%{ }^{\mathrm{a}}$ & $62.5 \% \mathrm{~b}$ & $51.6 \%$ c \\
\hline D12 CL diameter $\dagger$ & $16.3 \pm 2.4$ & $17.6 \pm 1.9$ & $16.5 \pm 2.7$ \\
\hline
\end{tabular}

a,b,c = within the row, cells with superscripts a,b,c differ $(P<0.05)$ from each other, $\dagger=$ measurements were in mean $\pm \mathrm{SE}, \dagger_{\dagger}=$ heifers with follicle $\geq 10 \mathrm{~mm}$ on D0 and CL on the same site $48 \mathrm{~h}$ later, $\dagger+\dagger=$ heifers that had no CL on D0 but with new CL on D7 


\section{Conception rate}

Among heifers inseminated, the pregnancy rate on day 32 was significantly less $(P<0.05)$ in the GPG group than in CIDR-GPG and CIDR-P-G groups (Table 5). Similarly, pregnancy was significantly higher $(P<0.05)$ in heifers that received $\mathrm{GnRH}$ at CIDR insertion than heifers without CIDR insert.

In all the 3 treatment protocols, heifers that ovulated within the first $24 \mathrm{~h}$ after TAI had a higher pregnancy rate than heifers ovulated after $24 \mathrm{~h}$ of insemination (Table 5). Cycling heifers at day 0 had a greater pregnancy rate compared to non-cycling heifers.

Table 5. Pregnancy rates in the three groups as affected by different factors

\begin{tabular}{|c|c|c|c|}
\hline \multirow[t]{2}{*}{ Factors considered } & \multicolumn{3}{|c|}{ Pregnancy $(\%$, No) } \\
\hline & GPG & CIDR-GPG & CIDR-P-G \\
\hline \multicolumn{4}{|l|}{ Ovulation within $24 \mathrm{~h}$ before TAI } \\
\hline № of heifers (\%) & $4(21.1 \%)$ & $7(25 \%)$ & $5(20.8 \%)$ \\
\hline №_pregnant (\%) & $3(75 \%)$ & $4(57.1 \%)$ & $2(40 \%)$ \\
\hline \multicolumn{4}{|l|}{ Ovulation within $24 \mathrm{~h}$ after TAI } \\
\hline № of heifers (\%) & $15(78.9 \%)$ & $21(75 \%)$ & $19(71.2 \%)$ \\
\hline №pregnant (\%) & $8(53.3)$ & $14(66.7 \%)$ & $13(68.4 \%)$ \\
\hline P. value & 0.002 & 0.01 & 0.003 \\
\hline \multicolumn{4}{|l|}{ D0 luteal activity } \\
\hline № cycling (\% pregnant) & $8(44.4 \%)$ & $12(57.1 \%)$ & $10(52.6 \%)$ \\
\hline № non-cycling (\% pregnant) & $3(30.0 \%)$ & $6(54.5 \%)$ & $5(41.7 \%)$ \\
\hline P. value & 0.014 & 0.07 & 0.001 \\
\hline Overall P/TAI & $39.3 \%(11 / 28)$ & $56.3(18 / 32)$ & $48.4 \%(15 / 31)$ \\
\hline
\end{tabular}

\section{Discussion}

The slightly shorter estrus onset to ovulation in induced estrus compared to natural estrus was probably due to exogenous PGF2a which causes luteolysis and reduced progesterone concentration, which allows heifers to express estrus earlier than heifers under natural luteolysis. The estrus duration in both induced (18.4 $\pm 4.2 \mathrm{~h})$ and natural estrus $(20.2 \pm 3.9 \mathrm{~h})$ groups were longer than of the previous report of Roelof et al. (2004) and Stevenson et al. (1998) who studied pure Holstein dairy heifers. Animal breed, management, and the environment may be among the factors that majorly contribute to the difference. The 
disparity of results may also be due to differences in scoring estrus as Roelof $e t$ al. (2004) considered estrus when the sum of points during consecutive observation periods exceeded 100 as compared to 50 points considered in this study.

According to Yoshida and Nakao (2005), the average duration of standing estrus was $6.2 \pm 3.9 \mathrm{~h}$ in Japan's dairy heifers which was slightly shorter than the average duration of standing estrus $(7.1 \mathrm{~h}$ in induced and $8.6 \mathrm{~h}$ in natural estrus) of the present study. The same authors reported all the 10 heifers observed exhibited standing estrus. Heifers are considered to experience lesser stresses and therefore, should express strong estrus signs. However, in our study, only $63.5 \%$ from induced and $54.5 \%$ from the natural estrus group exhibited standing estrus behavior. Other authors (van Eerdenburg et al., 1996; Le Blanc et al., 1998; Lyimo et al., 2000; van Eerdenburge et al., 2002) reported that standing estrus behavior is not seen in many heifers and cows at different dairy farms. Some of the possible reasons for the lack of standing estrus behavior may be due to inherent breed effects and/or excessive animal handling for daily transrectal ultrasonic evaluation.

The present time interval from estrus onset to ovulation in induced (30.7 \pm 1.6$)$ and natural estrus $(32 \pm 0.8 \mathrm{hrs})$ was longer than the $27.7 \pm 2.4 \mathrm{~h}$ and $26.1 \pm 1.2 \mathrm{~h}$ previously reported for induced and natural estrus groups, respectively (Pinheiro et al., 1998). Similarly, Son et al. (2007) reported that ovulation occurred at $25.55 \pm 5.72 \mathrm{~h}$ after the onset of estrus in dairy heifers. The differences may be possibly due to breed, and nutrition effects. Energy balance is known to affect reproduction in dairy cattle as reported by some authors (Wathes et al., 2007; Van Hoeck et al., 2014).

In the current study, the time interval between onset and end of most sexual estrus behaviors to ovulation showed large gap (range). The exceptions were standing to be mounted and mounting other heifers which showed lower variation and were easily detectable visually. Since all heifers that manifested mounting activities finally ovulated, signs related to mounting activities better-predicted ovulation time in this study. However, only $63.6 \%$ of heifers from induced and $54.5 \%$ from natural estrus groups were in standing estrus, which means when only standing estrus was considered heifers not in standing estrus could be missed. Lyimo et al. (2000) concluded that standing estrus, the standard symptom of estrus, was not the primary symptom for detecting estrus in cows as it was observed in only $53 \%$ of the cows.

Ethiop. Vet. J., 2021, 25 (2), 115-131 
Ovulatory follicle size is known to be affected by animal breed. In the present study, ovulation occurred at ovulatory follicle diameters range of $10 \mathrm{~mm}$ to $19 \mathrm{~mm}$. The study of Gimenes et al. (2008) indicated that B. indicus cattle can ovulate from the follicle as small as $7 \mathrm{~mm}$ in contrast to Holstein cattle which only ovulate from follicles with $10 \mathrm{~mm}$ or more. Studies of Sartorelli et al. (2005) and Carvalho et al. (2008) indicate that ovulatory follicle diameter frequently ranges from 10 to $13 \mathrm{~mm}$ in Bos indicus. In Holstein cattle, ovulation frequently occurs at a diameter of between 12 and 22mm (Savio et al., 1988; Ginther et al., 1989; Carvalho et al., 2008). In one study (Alvarez et al., 2000); ovulatory follicle was larger in Bos indicus than in Bos taurus cattle.

In the present study, the day 10 corpus luteum size of crossbred heifers ranged from $10 \mathrm{~mm}$ to $22.6 \mathrm{~mm}$. The study of Carvalho et al. (2008) indicated that on day 10 after ovulation corpus luteum was smaller $(15.3 \mathrm{~mm})$ in $B$. indicus cattle than in $B$. taurus heifers $(18.4 \mathrm{~mm})$. Corpora lutea size can be as large as $24.1 \mathrm{~mm}$ diameter for Holstein heifers (Sartori et al. (2004). In Nellore cattle (B. indicus) corpus luteum size range from $15.6 \mathrm{~mm}$ diameter to $21.5 \mathrm{~mm}$ diameter in the reports of Figueiredo et al. (1997) and Mollo et al. (2007).

Lima et al. (2010) compared the cost of timed AI and natural service using as inputs of reproductive results and economical information and, reported that the cost of pregnancy was less for timed AI than natural service. In the present study, Ovsynch protocol in absence of progestin (CIDR) resulted in a low conception rate to TAI (39.3\%) in crossbred heifers. Similarly, previous studies (Pursley et al., 1995; Schmitt et al., 1996; Pursley et al., 1997; Tenhagen et al., 2005) indicated low pregnancy to TAI in Holstein heifers synchronized by Ovsynch protocol in absence of progestin. Tenhagen et al. (2005) proposed the limited success of Ovsynch protocol in heifers is suspected to be caused by the follicular dynamics of heifers that differs from that of lactating dairy cows.

The conception rate to TAI (56.3\%) in the CIDR-GPG group in the present study was consistent with Colli et al. (2016) who reported $57.3 \%$ and $57.1 \%$ in crossbred (Angus $X$ Nelore) heifers. However, in the work of Colli et al. (2016), the PGF2a was given twice, on day 0 and on the day of CIDR removal in the first group and two days prior to device removal in the second group heifers. Mendanha et al. (2012) reported lower conception to TAI (40.3\% and 42.1\%) in Girolando heifer when the PGF was given as in the work of Colli et al. (2016). The result indicates that animal breed and treatment protocol among the oth- 
ers affect conception rate to TAI. Many other factors like sexual maturity of heifers, weight after weaning, and development of the reproductive tract may be the source of difference.

The lower pregnancy rate (48.4\%) in CIDR-P-G heifers with a moderate ovulation rate (77.4\%) may be due to the absence of treatment with $\mathrm{GnRH}$ on day 0 in this group. GnRH ovulates the dominant follicle (Pursley et al., 1995) and prevents the formation of a persistent dominant follicle in heifers without CL at CIDR insert. Progestin treatment in the absence of a functional CL has been shown to result in the development of a persistent follicle resulting in poor pregnancy rates and oocytes ovulated from persistent follicles are known to be less fertile (Revah and Butler, 1996; Mihm et al., 1999). Similarly, Bello et al. (2006) reported that synchronization response to Ovsynch was higher $(87.9 \%)$ in cows that ovulated in response to the first GnRH of Ovsynch compared with those that did not (62.9\%).

The variation in ovulation to treatment with $\mathrm{GnRH}$ on day 0 was probably due to the stage of follicular wave development at the time of $\mathrm{GnRH}$ injection and/ or differences in concentrations of gonadotropins, estrogen, inhibin, or progesterone at GnRH injection (Ireland et al., 2000; Thatcher et al., 2002). The work of Moreira et al. (2000) showed that initiation of Ovsynch on days 5 to 9 of the estrous cycle was a key to successful synchronization of ovulation.

\section{Conclusions}

Ovulation synchronization without CIDR insert leads to premature estrus manifestation and reduced fertility to timed insemination in crossbred heifers. Combining GnRH and CIDR at the start of ovulation synchronization increase follicle turnover, induce ovulation, and enhance new corpus luteum formation and increases fertility. Standing to be mounted and mounting other heifers are the best predictor for the time of ovulation, however, these behaviors were not seen in some heifers.

\section{Acknowledgments}

The authors want to thank dairy farmers included in the study for allowing us to use heifers. We thank Addis Ababa University for partial financial support. 
The authors also want to thank a technician that involved in estrus detection and the one involved in insemination work.

\section{References}

Alvarez, P., Spicer, L. J., Chase, C. C., Payton, M. E., Hamilton, T. D., Stewart, R. E, et al., 2000. Ovarian and endocrine characteristics during an estrous cycle in Angus, Brahman, and Senepol cows in a subtropical environment. J Anim Sci., 78, 1291-1302.

Bello, N. M., Steibel, J. P. and Pursley, J. R. 2006. Optimizing ovulation to first GnRH improved outcomes to each hormonal injection of Ovsynch in lactating dairy cows, J. Dairy Sci. 89, 3413-3424.

Carvalho, J. B. P., Carvalho, N. A. T., Reis, E.L., Nichi, M., Souza, A. H. and Baruselli, P. S., 2008. Effect of early luteolysis in progesterone-based timed AI protocols in Bos indicus, Bos indicus x Bos taurus, and Bos taurus heifers. Theriogenology., 69,167-175.

Colli M. H. A., Carvalhaes, R. P. A., Mingoti, R. D., Vieira, L. M., Rezende, R. G., Santos, M. H., et al., 2016. Pregnancy rate to FTAI of crossbred heifers (B. indicus $\mathrm{x} B$. taurus) submitted to protocols of 3 or 4 handling cattle. Anim Reprod., 13, 425-437

CSA, 2017. Livestock and livestock characteristics from agricultural sample survey. Central Statics Agency of Ethiopia. Volume II. https:/www.statsethiopia.gov.et/

Ferguson, J. D., Galligan, D. T. and Thomsen N., 1994. Principal descriptors of body condition score in Holstein cows. J. Dairy Sci., 77, 2695-2703.

Figueiredo, R. A., Barros, C.M., Pinheiro, O. L. and Soler, J. M. P., 1997. Ovarian follicular dynamics in Nelore breed (Bos indicus) cattle. Theriogenology., 47, 1489-1505.

Fricke, P. M., Guenther, J. N. and Wiltbank, M. C., 1998. Efficacy of decreasing the dose of GnRH used in a protocol for synchronization of ovulation and timed AI in lactating dairy cows. Theriogenology. 50, 1275-1284.

Gimenes, L. U., Sa' Filho, M. F., Carvalho, N. A. T., Torres-Ju'nior, J. R. S., Souza, A. H., Madureira , E. H.., et al, 2008. Follicle deviation and ovulatory capacity in Bos indicus heifers, Theriogenology., 69: 852-858.

Ginther, O. J., Knopf, L. and Kastelic, J. P.,1989. Temporal associations among ovarian events in cattle during oestrous cycles with two or three follicular waves. $J$ Reprod Fertil., 87, 223-230.

Gizaw, S., Tesfaye, Y., Mekuriaw, Z., Tadesse, M., Hoekstra, D., Gebremedhin, B. and Tegegne A. 2016. Oestrus synchronization for accelerated delivery of improved dairy genetics in Ethiopia: Results from action research and development inter- 
ventions. LIVES Working Paper Nairobi, Kenya: International Livestock Research Institute (ILRI). visit http:// creativecommons.org/licenses/by-nc-sa/3.0/

Hiers, E., Barthle, A., C. R., Dahms, M. K. V., Portillo, G. E., Bridges, G. A., Rae, D. O., et al., 2003. Synchronization of Bos indicus $\times$ Bos taurus cows for timed artificial insemination using gonadotropin-releasing hormone plus prostaglandin F2a in combination with melengestrol acetate. J. Anim. Sci., 81, 830-835.

Ireland, J. J., Mihm, M., Austin, E., Diskin, M. G. and Roche, J. F. 2000. Historical perspective of turnover of dominant follicles during the bovine estrous cycle: Key concepts, studies, advancements, and terms. J. Dairy Sci. 83,1648-1658.

LeBlanc, S. J., Leslie, K. E., Ceelen, H. J., Kelton, D. F., and Keefe. G. P., 1998. Measures of estrus detection and pregnancy in dairy cows after administration of gonadotropin-releasing hormone within an estrus synchronization program based on prostaglandin F2alpha. J. Dairy Sci. 81, 375-381.

Lima, F. S., De Vries, A., Risco, C. A., Santos, J. E. P., and Thatcher, W. W., 2010. Economic comparison of natural service and timed artificial insemination breeding programs in dairy cattle. J Dairy Sci. 93, 2010.

Lyimo, Z. C., Nielen, M., Ouweltjes, W., Kruip, T. A. M. and van Eerdenburg, F. J. C. M., 2000. Relationship among estradiol, cortisol, and intensity of estrous behavior in dairy cattle. Theriogenology. 53,1783-1795.

Martínez, M. F., Kastelic, J. P., Bo, G. A., Caccia, M. and Mapletoft, R. J., 2005. Effects of oestradiol and some of its esters on gonadotropin release and ovarian follicular dynamics in CIDR-treated beef cattle. Anim. Reprod. Sci. 86, 37-52.

Mendanha, M.F., Sala, R.V., Reis, T.A.N.P.S., Carvalho, F.J., Guimaes, L.H.C., Macedo, G.G., et al., 2012. Momento da administração de prostaglandina e número de utilizações do dispositivo de progesterone na eficiência da IATF en novilhas girolando. In: Anais da XXXVI Reunião Annual da Sociedade Brasileira de Tecnologia de Embriões (SBTE) Fóz do Iguacu, PR, Brazil For do Iguacu: SBTE. pp. 370. (abstract).

Mihm, M., Curran, N.., Hyttel, P., Knight, P. G., Boland, M. P., and Roche, J. F. 1999. Effect of dominant follicle persistence on follicular fluid oestradiol and inhibin and on oocyte maturation in heifers. J Reprod Fertil., 116, 293-304.

Mollo M. R., Rumpf, R., Martins, A. C., Mattos, M. C. C., Jr, G. Lopes., and Carrijo, L. H. D., 2007. Ovarian function in Nelore heifers under low or high feed intake. Acta Sci. Vet. 35, 958.

Moreira, F. R., de la Sota, L., Diaz, T. and Thatcher, W. W. 2000, Effect of day of the estrous cycle at the initiation of a timed artificial insemination protocol on reproductive responses in dairy heifers, J. Anim. Sci. 78, 1568-1576.

Ethiop. Vet. J., 2021, 25 (2), 115-131 
Pinheiro, O. L., Barros, C. M., Figueiredo, R. A., do Valle, E. R., Encarna, R. O. and Padovani, C. R., 997. Estrous behavior and the estrus-to-ovulation interval in Nellore cattle (Bos indicus) with natural estrus or estrus induced with prostaglandin F2a or norgestomet and estradiol valerate, Theriogenology., 49, 667-681.

Pursley, J. R., Mee. M. O. and Wiltbank, M. C., 1995. Synchronization of ovulation in dairy cows using PGF2a and GnRH. Theriogenology. 44, 915-23.

Revah, J. and Butler, W. R. 1996. Prolonged dominance of follicles and reduced viability of bovine, J Reprod Fertil., 106, 39-47.

Rivera, H., Lopez, H., and Fricke, P. M., 2004. Fertility of Holstein dairy heifers after synchronization of ovulation and timed AI or AI after removed tail chalk. J. Dairy Sci. 87, 2051-2061.

Roelf, J. B., Bouwman, E. G., Dieleman, S. J., Van Eerdenburg, F. J. C. M., Kaal-Lansbergen, L. M. T. E., Soede, N. M. and Kemp, B., 2004. Influence of repeated rectal ultrasound examinations on hormone profiles and behaviour around oestrus and ovulation in dairy cattle. Theriogenology. 62, 1337-52.

Sartorelli, E. S., Luciano Carvalho, M., Bergfelt, D. R., Ginther, O. J. and Barros, Ciro, M., 2005. Morphological characterization of follicle deviation in Nelore (Bos indicus) heifers and cows, Theriogenology., 63, 2382-2394.

Sartori, R., Haughian, J. M., Shaver, R. D., Rosa, G. J. M. and Wiltbank, M. C., 2004. Comparison of ovarian function and circulating steroids in estrous cycles of Holstein heifers and lactating cows. J. Dairy Sci. 87, 905-920.

Son, D-S., Choe, C-Y., Choi, S-H., Rae-Cho, S., Kim, H-J., Han, M-H., Ryu, II-S., Suh, G-H., Kim, U-H., Kim, I-H., 2007. Effect of estradiol benzoate or GnRH treatment prior to super stimulation in CIDR-treated, Korean native cows (Bos taurus). Anim. Reprod. Sci., 100, 14-21

Stevenson, J. S., Lamb, G. C., Kobayashi, Y., and Hoffman, D. P., 1998. Luteolysis during two stages of the estrous cycle: Subsequent endocrine profiles associated with radio telemetrically detected estrus in heifers. J. Dairy Sci. 81, 2897-2903.

Tenhagen, B. A., Kuchenbuch, S. and Heuwieser, W. 2005. Timing of ovulation and fertility of heifers after synchronization of oestrus with GnRH and Prostaglandin F2a. Reprod Dom Anim., 40, 62-67.

Thatcher, W. W., Moreira, F., Pancarci, S. M., Bartolome, J. A. and Santos, J. E. 2002. Strategies to optimize reproductive efficiency by regulation of ovarian function. Domest. Anim. Endocrinol. 23, 243-254.

Van Eerdenburg F. J. C. M., Karthaus, D., Taverne, M. A. M., Merics, I. and Szenci, O., 2002. The relationship between estrous behavioral score and time of ovulation in dairy cattle. J. Dairy Sci., 85, 1150-1156. 
Van Eerdenburg, F. J. C. M., Loeffler, S. H. and Van Vliet J. H., 1996. Detection of oestrus in dairy cows: a new approach to an old problem. Vet Quart., 18, 52-54.

Van Hoeck, V., P. E. Bols, M. Binelli and J. L. Leroy, 2014. Reduced oocyte and embryo quality in response to elevated non-esterified fatty acid concentrations: a possible pathway to subfertility? Anim. Reprod. Sci. 149:19-29.

Wathes, D. C., Pollott, G. E., Johnson, K. F., Richardson, H. and Cooke, J. S., 2014. Heifer fertility and carry-over consequences for lifetime production in dairy and beef cattle, Animal (The Animal Consortium 2014, 8: s1, pp 91-104.

Yoshida, C and Nakao, T., 2005. Some characteristics of primary and secondary estrous signs in high-producing dairy cows. Reprod Dom Anim. 40, 150-155. 